\title{
Optimization of some physical parameters for the production of gluconic acid by a mutant gluconobacter oxydans GPM 60
}

\author{
Ganguly S. ${ }^{1}$, Patra S.K. ${ }^{2}$ and Mandal S.K. ${ }^{3}$ \\ ${ }^{1}$ Department of Biological Sciences, Sankrail A. C. High School (H.S.), Sankrail, Howrah, \\ West Bengal, India, Mob-9830311251, subhadeepgangulyphysiol@rediffmail.com \\ ${ }^{2}$ Department of Physiology Surendranath College, Kolkata, West Bengal, India \\ ${ }^{3}$ Department of Organon of Medicine, Midnapore Homeopathic medical college and Hospital, Midnapore, \\ West Bengal, India
}

\begin{abstract}
The microbial production of gluconic acid has been investigated using a mutant Gluconobactor oxydans GPM 60 through optimization of some Physical parameters. Production conditions like initial pH, incubation period, volume of media, age of inoculum, volume of inoculum, agitation and temperature were individually opitimized one by one. The maximum yield of gluconic acid is $13.80 \mathrm{~g} / \mathrm{L}$ with pH 6.0, 96h incubation, $20 \mathrm{ml}$ medium, $48 \mathrm{~h}$ age of inoculum, $10 \mathrm{ml}$ volume of inoculum, $250 \mathrm{rpm}$ agitation and $300 \mathrm{C}$ temperature.

Keywords: Gluconic acid, mutant, optimization, physical parameters, inoculum
\end{abstract}

\section{Introduction}

Gluconic acid is a non-corrosive, non-volatile, non-toxic, mild organic acid [1]. It imparts a refreshing sour taste in many food items such as wine, fruit juice etc [2]. It is aboundantly found in plants, fruits, rice, meat, milk products, wine, honey vinegar etc [3]. It is widely used in food industries for pickling of foods, in baked goods as a component of leaving agent for preleavened products, as flavouring agent [4]. It is also applicable for the reduction of fat absorption in donghnuts and cones [5]. It has also got some pharmaceutical and hygienic applications such as minerals suppliments to prevent deficiencies of different salts of calcium, sodium, zinc etc. [6]. Considering its rapid increase in different industries, the microbial production of gluconic acid was started since 1870 by Hasiwetz and Habermann who first discovered this organic acid [7]. A continuous to increase its industrial production was carried out to increase its industrial production was carried out using different microorganisms including many bacteria like pseudomonas savastanoi, gluconobacter oxydans, acetobacter methanolicus; yeast and different fungus like aspergillus niger etc. [8]. In this present study, our major aim was to optimize some physical parameters to increase the production of gluconic acid by this mutant strain.

\section{Materials and Methods}

Microorganism: Gluconobacter oxydans was isolated from the sail at sankrail, Howrah, West Bengal. The parent strain produced only $0.9 \mathrm{~g} / \mathrm{L}$ gluconic acid. To develop a high yielding strain from this strain we exposed it to achemical mutagen Ethyl methane Sulphonatee (EMS). About 268 mutant strains were isolated from this mutagenic study. Of them gluconobacter oxydans GPM60 produced maximum gluconic acid (6.3 $\mathrm{g} / \mathrm{L})$. This strain was used throughout the study. Medium for gluconic acid production : Production medium contained glucose, $10 \%$; urea, $0.9 \%$;
K2HPO4, $0.1 \%$; MgSO4, $7 \mathrm{H} 2 \mathrm{O}, 0.5 \%$; Yeast extract, $0.4 \%$; $\mathrm{pH} 7.0$. Fermentation was carried out using the shake flask method on a temperature controlled shaker $\mathrm{BOD}$ incubator with shaker) shaking at $150 \mathrm{rpm}$ for $72 \mathrm{~h}$ at $280 \mathrm{C}$. Analysis of gluconic acid: Gluconic acid was measured by isotachophoretic method [9]. Estimation of residual sugar: The residual sugar was estimated by DNS method [10]. Determination of Dry Cell Weight (DCW) : The fermentation broth was centrifuged at 10,000 rpm and then $3 \mathrm{ml}$ of $1(\mathrm{~N}) \mathrm{HCl}$ was poured into the bacterial cell precipitate and calcium carbonate to dissolve calcium carbonate. The remaining bacterial cells were washed with water and dried at $100 \circ \mathrm{C}$ until the cell weight remains constant [11].

\section{Statistical Analysis}

All data were expressed as mean \pm SEM. All data in the present study were analyzed by the one way ANOVA followed by Dunett's post - hoc test for multiple comparisons of the treatment means using 'prism 4.0' soft were (Graph pad Inc., USA). A "p" value less than 0.05 was considered significant and less than 0.01 was considered highly significant.

\section{Discussion}

Effect of initial $\mathrm{pH}$ : The $\mathrm{pH}$ of the fermentation broth was adjusted using $0.1(\mathrm{~N}) \mathrm{HCl}$ and $0.1(\mathrm{~N})$ $\mathrm{NaOH}$. The effect of $\mathrm{pH}$ on gluconic acid fermentation was studied using different levels $(4.0-7.0)$ of initial $\mathrm{pH}$ of the medium. The gluconic acid production was maximum at $\mathrm{pH} 6.0$ (Table -1). The production of weak organic acid like citric acid, gluconic acid etc. is a function of the $\mathrm{pH}$ of the fermentation medium [12]. The $\mathrm{pH}$ range of different microorganism including fungus and bacteria for gluconic acid production was around 4.5 to 7.0 [13]. 


\section{Effect of period of incubation}

To optimize the period of incubation for the production of gluconic acid, the fermentation broth was incubated for different periods (24 $168 \mathrm{~h}$ ), and it was found that at $96 \mathrm{~h}$ of incubation, the production was maximum (Table -2$)$.

\section{Effect of volume of media}

Different volumes $(15-35 \mathrm{ml})$ of media were inoculated and incubated to access the optimal volume for this organic acid production (Table 3). $20 \mathrm{ml}$ medium was proved to be most suitable. Excess medium volume may dilutee the acid content, where as small volume give insufficient nutrient for the growth of the microorganism leading to decreased accumulation of desired metabolites [14].

\section{Effect of age of inoculum}

To examine the suitable inoculum age we have studied five different ages $(24-12 \mathrm{~h}$ ) of inocula (Table - 4). $48 \mathrm{~h}$ aged inoculum gave maximum production. Different reviews suggest that the production of secondary metabolites like gluconic acid was maximum at late lag and early log phases of bacterial growth [15 - 18]. Thus, it is necessary to determine those phases for that particular bacterium to be used.

\section{Effect of volume of inoculum}

Cell density is another impartant factor for the production of gluconic acid. To examine the optimum cell density, different volumes of inocula (5-12 ml) were studies. In our present study we found that $10 \mathrm{ml}$ inoculum showed maximum production (Table-5). Nakyama et al (1961) [19] claimed $10 \mathrm{ml}$ inoculum size is most suitable for the production of different secondary metabolites. But it may not fair to say that $10 \mathrm{ml}$ inoculum size is required for all microbial strains because it depends upon another two major factors viz., cell mass and composition of the medium [20].

\section{Effect of agitation}

Oxygen availability of the fermentation broth is a very crucial factor for gluconic acid production, because its production requires oxidation of glucose which highly oxygen dependent process [21]. However, oxygen is poorly soluble in water. Therefore, agitation is necessary to dissolve the oxygen in liquid fermentation medium [22]. In our present investigation six different (50-300 rpm) shaker speed were examined to access the most suitable agitation rate (Table-6). $200 \mathrm{rpm}$ was proved to be most suitable one.

\section{Effect of temperature}

The growth of the microorganism is a function of temperature through a series of metabolic sequences [23]. Change of temperature will shift the metabolic utilization rate of one component as compared to another thus impairs the growth rate [24]. The early depletion of some essential nutrient can shift the culture from balanced to unbalanced state and thus influences its performance [25]. The effect of different temperature $(25-350 \mathrm{C})$ on, gluconic acid production declines sharply (Table -7$)$.

\section{Conclusion}

The present study indicates that a relatively good yield of gluconic acid can be obtained after optimization of certain physical conditions for fermentation by the mutant strain Gluconobactor oxydans GMP60. However, in the present investigation, only limited parameters were examined. An attempt to scale up the process is under way.

\section{Acknowledgement}

We express our sincere gratitude to the Department of Chemical Engineering, University of Calcutta and Sankrail A. C. Highs School $(\mathrm{H}$. S.) for providing necessary help. We also express our thanks to the librarians of Bose Institute, Kolkata and Indian Institute of Chemical Biology (IICB) for providing us necessary library facilities.

\section{References}

[1] Moyer A. J. (1940) US patent No. 2351500, chem. Abstr. 38, 5360.

[2] Rohr M., Kubicek C. P., Kominek J. (1983) Biotechnology, 3.

[3] Rehm H. J., Reed G. (Eds.), Verlag Chemie, Weinheim, Germany (1983) $455-465$

[4] Currie J. N., Carter R. H. (1930) US Patent No. 1896811

[5] Singh O. V., Jain R. K., Singh R. P. (2003) J. Chem. Technol. Biotechnol, 78, $208-$ 212.

[6] Moksia J., Larroche C., Gros J. B. (1996) Biotechnol. Lett. 18, 1025 - 1030.

[7] Vassilev N. B., Vassileva M. C., Spassova D. I. (1993) Appl. Microbiol. Biotechnol. $39,285-288$.

[8] Stubbs J. J., Lockwood L. B., Roe E. T., Tabenkin B., ward G. E. (1940) Ind. Eng. Chem. 32, $1626-1630$.

[9] Curie J. N., Kane J. H., Finlay A (1931) US patent No. 1893819. Chem. Abstr 27, 2249. Chem. Abstr 27, 2249.

[10] Everaerts F. M., Beckers J. L., Verheggen T. P. E. M. (1976) Isotachopho. resis Theory, Instrumentation and Applicatioons, Elsevier, Amsterdam, The Netherlands.

[11] Miller G. L. (1959) Anal. Chem. 31, 426 428.

[12] Shah A. H. (1998) PhD Thesis, Quaid - I. Azam University, Islamabad, Pakistan.

[13] Ambati P., Ayyanna C. (2001) World J Microbiol Biotechnol. 17, 331 - 335. 
[14] Tran C. T., Mitchell D. A. (1995) Biotechnol lett, 17, $1107-1110$.

[15] Milsom P. E. (1987) Food Biotechnology 1 , edited by king $R$. D. and cheetam $P$. S. J. (Applied Science, London and New York), 273 - 306.

[16] Sankpal N. V., Kulkarni B. D. (2002) Process Biochem. 37, 1343 - 1350.

[17] Nelson R. P. (1974) US. Patent No. 39577580.

[18] Moyer A. J., Welss P.A., Stubbs J. J., Herrick H. T., May O. E. (1937) Ind. Eng. Chem. 29, 777 - 781.

[19] Bernhauer K. (1924) Biochem. Z. 153, 517521.
[20] Nakayama K., Kitadah S., Seto Z., Kinoshita S. (1961) J. Gen. Appl. Microbiol. 7, $41-51$.

[21] Znad H., Markos J., Bales V. (2004) Process Biochem. 39, 1341 - 1345.

[22] Wells P. A., Moyer A. J., Stubbs J. J., Herrick H. T., May O. E., (1937) Ind. Eng. Chem. 29, $635-656$.

[23] May O. E., Herrick H. T., Moyer A. J., Wells P.A. (1934) Ind. Eng. Chem., 26, 575 578.

[24] Stadler - Szoke A., Nyeste L., Hollo J. (1980) Acta Aliment. 9, 155 - 172.

[25] Velizarov S., Beschkov V. (1994) Biotechnol. Lett. 16, 715 - 720.

[26] Milsom P. E., Merrs J. L. (1985) Compr. Biotechnol. 3, $681-700$.

Table 1: Effect of initial $\mathrm{pH}$ on gluconic acid production

\begin{tabular}{|l|l|l|l|}
\hline Initial $\mathrm{pH}$ & Gluconic acid $(\mathrm{g} / \mathrm{L})$ & $\mathrm{DCW}(\mathrm{g} / \mathrm{L})$ & Residual sugar $\%$ \\
\hline 4.0 & $4.8 \pm 0.02$ & $0.99 \pm 0.01^{* *}$ & $14.16 \pm 0.17^{*}$ \\
\hline 4.5 & $5.7 \pm 0.06 \#$ & $1.71 \pm 0.07^{*}$ & $13.83 \pm 0.11^{*}$ \\
\hline 5.0 & $6.5 \pm 0.01 \#$ & $1.94 \pm 0.03 \#$ & $13.41 \pm 0.13 \#$ \\
\hline 5.5. & $6.9 \pm 0.01 \#$ & $1.97 \pm 0.01 \#$ & $13.17 \pm 0.11 \#$ \\
\hline 6.0 & $7.6 \pm 0.05^{*}$ & $2.08 \pm 0.06 \#$ & $12.71 \pm 0.16^{*}$ \\
\hline 6.5 & $7.2 \pm 0.01^{*}$ & $2.00 \pm 0.03 \#$ & $12.44 \pm 0.14^{*}$ \\
\hline$\bullet \quad 7.0$ & $6.3 \pm 0.03$ & $1.93 \pm 0.01$ & $13.42 \pm 0.11$ \\
\hline $7.5 \quad$ & $1.89 \pm 0.05 \#$ & $13.53 \pm 0.16 \#$ \\
\hline
\end{tabular}

Table 2: Effect of incubation period on gluconic acid production

\begin{tabular}{|l|l|l|l|}
\hline Period of incubation(h) & Gluconic acid(g/L) & DCW(g/L) & Residual sugar \% \\
\hline 24 & $5.8 \pm 0.01^{\star \star}$ & $1.72 \pm 0.01^{\star *}$ & $13.81 \pm 0.13^{* *}$ \\
\hline 48 & $6.6 \pm 0.03^{*}$ & $1.95 \pm 0.09 \#$ & $13.27 \pm 0.11^{*}$ \\
\hline$\bullet$ & $7.2 \pm 0.04$ & $2.00 \pm 0.02$ & $12.44 \pm 0.10$ \\
\hline 96 & $8.6 \pm 0.07^{*}$ & $2.20 \pm 0.01^{* *}$ & $11.81 \pm 0.31^{*}$ \\
\hline 120 & $8.1 \pm 0.03^{*}$ & $2.13 \pm 0.03^{*}$ & $11.93 \pm 0.16^{*}$ \\
\hline 144 & $7.7 \pm 0.01 \#$ & $2.09 \pm 0.02 \#$ & $12.70 \pm 0.11^{*}$ \\
\hline 168 & $6.9 \pm 0.06 \#$ & $1.97 \pm 0.01 \#$ & $13.17 \pm 0.27^{*}$ \\
\hline
\end{tabular}

$\mathrm{n}=6$; values were expressed as mean \pm SEM

${ }^{*} p<0.05 ;{ }^{* *} p<0.01$; \# non significant; $\bullet$ Control

Table 3: Effect of volume of media on gluconic acid production

\begin{tabular}{|c|c|c|c|}
\hline Volume of media (ml) & Gluconic acid(g/L) & $\mathrm{DCW}(\mathrm{g} / \mathrm{L})$ & Residual sugar \% \\
\hline 15 & $8.1 \pm 0.01 \#$ & $2.13 \pm 0.02$ * & $11.93 \pm 0.19 \#$ \\
\hline 20 & $9.3 \pm 0.03 \#$ & $2.27 \pm 0.03 \#$ & $11.43 \pm 0.11 \#$ \\
\hline 25 & $8.9 \pm 0.01 \#$ & $2.23 \pm 0.01 \#$ & $11.63 \pm 0.27 \#$ \\
\hline 30 & $8.6 \pm 0.07$ & $2.20 \pm 0.01$ & $11.81 \pm 0.33$ \\
\hline 35 & $7.1 \pm 0.02$ * & $1.99 \pm 0.03^{* *}$ & $12.46 \pm 0.31 \#$ \\
\hline
\end{tabular}

Table 4: Effect of age of inoculum on gluconic acid production

\begin{tabular}{|l|l|l|l|}
\hline Age of inoculum $(\mathrm{ml})$ & Gluconic $\operatorname{acid}(\mathrm{g} / \mathrm{L})$ & $\mathrm{DCW}(\mathrm{g} / \mathrm{L})$ & Residual sugar \% \\
\hline 24 & $8.5 \pm 0.07 \#$ & $2.18 \pm 0.02 \#$ & $11.80 \pm 0.33 \#$ \\
\hline$\bullet$ & $9.3 \pm 0.03$ & $2.27 \pm 0.03$ & $11.43 \pm 0.11$ \\
\hline 72 & $8.7 \pm 0.03^{*}$ & $2.21 \pm 0.01$ \# & $11.90 \pm 0.33 \#$ \\
\hline 96 & $8.3 \pm 0.03^{*}$ & $2.14 \pm 0.01^{*}$ & $11.63 \pm 0.19 \#$ \\
\hline 120 & $7.6 \pm 0.01^{*}$ & $2.08 \pm 0.01^{\text {* }}$ & $12.71 \pm 0.23^{\text {** }}$ \\
\hline
\end{tabular}

$\mathrm{n}=6$; values were expressed as mean \pm SEM

${ }^{*} p<0.05$; ${ }^{* *} p<0.01$; \# non significant; $\bullet$ Control 
Table 5: Effect of volume of inoculum on gluconic acid production

\begin{tabular}{|l|l|l|l|l|}
\hline $\begin{array}{l}\text { Volume } \\
\text { inoculum }(\mathrm{ml})\end{array}$ & Cell density & Gluconic acid(g/L) & DCW(g/L) & Residual sugar \% \\
\hline 5 & $5 \times 10^{8}$ & $6.3 \pm 0.06^{* *}$ & $2.15 \pm 0.01^{*}$ & $13.42 \pm 0.23^{*}$ \\
\hline 6 & $6 \times 10^{8}$ & $7.9 \pm 0.01^{*}$ & $2.11 \pm 0.07^{*}$ & $12.71 \pm 0.19^{*}$ \\
\hline 7 & $7 \times 10^{8}$ & $8.6 \pm 0.01 \#$ & $2.20 \pm 0.01^{\#}$ & $11.81 \pm 0.31 \#$ \\
\hline$\bullet \quad 8 \times 10^{8}$ & $9.3 \pm 0.03$ & $2.27 \pm 0.03$ & $11.47 \pm 0.11$ \\
\hline 9 & $9 \times 10^{8}$ & $10.1 \pm 0.01 \#$ & $2.33 \pm 0.01^{*}$ & $10.63 \pm 0.09 \#$ \\
\hline 10 & $10 \times 10^{8}$ & $11.8 \pm 0.07^{*}$ & $2.51 \pm 0.07^{* *}$ & $9.86 \pm 0.13^{*}$ \\
\hline 11 & $11 \times 10^{8}$ & $11.1 \pm 0.03^{* *}$ & $2.47 \pm 0.06^{* *}$ & $10.19 \pm 0.19^{*}$ \\
\hline 12 & $12 \times 10^{8}$ & $10.9 \pm 0.01^{*}$ & $2.43 \pm 0.01^{* *}$ & $10.13 \pm 0.11^{*}$ \\
\hline
\end{tabular}

$n=6$; values were expressed as mean \pm SEM

${ }^{*} p<0.05$; ${ }^{* *} p<0.01$; \# non significant; • Control

Table 6: Effect of agitation of inoculum on gluconic acid production

\begin{tabular}{|l|l|l|l|}
\hline Agitation (rpm) & Gluconic acid(g/L) & DCW $(\mathrm{g} / \mathrm{L})$ & Residual sugar \% \\
\hline 50 & $9.2 \pm 0.02^{* *}$ & $2.26 \pm 0.01^{* *}$ & $11.49 \pm 0.19^{*}$ \\
\hline 100 & $10.3 \pm 0.01^{*}$ & $2.34 \pm 0.07^{* *}$ & $10.62 \pm 0.26^{*}$ \\
\hline$\bullet$ & $11.8 \pm 0.07$ & $2.51 \pm 0.01$ & $9.86 \pm 0.13$ \\
\hline 200 & $12.1 \pm 0.03 \#$ & $2.54 \pm 0.07 \#$ & $9.66 \pm 0.19 \#$ \\
\hline 250 & $12.6 \pm 0.03^{\#}$ & $2.59 \pm 0.03 \#$ & $9.87 \pm 0.21 \#$ \\
\hline 300 & $13.1 \pm 0.01^{\star *}$ & $2.71 \pm 0.07^{* *}$ & $10.19 \pm 0.11^{*}$ \\
\hline
\end{tabular}

$\mathrm{n}=6$; values were expressed as mean \pm SEM

${ }^{*} p<0.05 ;{ }^{* *} p<0.01$; \# non significant; $\bullet$ Control

Table 7: Effect of temperature of inoculum on gluconic acid production

\begin{tabular}{|c|c|c|c|}
\hline Temparrature (oc) & Gluconic acid(g/L) & $\mathrm{DCW}(\mathrm{g} / \mathrm{L})$ & Residual sugar \% \\
\hline 25 & $10.3 \pm 0.01^{* *}$ & $2.34 \pm 0.02^{* \star}$ & $10.63 \pm 0.21$ * \\
\hline 26 & $11.1 \pm 0.02$ * & $2.47 \pm 0.01^{*}$ & $10.19 \pm 0.11^{*}$ \\
\hline 27 & $11.9 \pm 0.01 \#$ & $2.51 \pm 0.03 \#$ & $9.88 \pm 0.27 \#$ \\
\hline 28 & $12.1 \pm 0.01$ & $2.54 \pm 0.07$ & $9.61 \pm 0.19$ \\
\hline 29 & $12.7 \pm 0.01 \#$ & $2.58 \pm 0.03 \#$ & $9.33 \pm 0.13 \#$ \\
\hline 30 & $13.8 \pm 0.06^{* *}$ & $2.75 \pm 0.01^{* *}$ & $8.31 \pm 0.19^{*}$ \\
\hline 31 & $13.2 \pm 0.03$ * & $2.71 \pm 0.02$ ** & $8.92 \pm 0.11$ * \\
\hline 32 & $12.6 \pm 0.07 \#$ & $2.59 \pm 0.01 \#$ & $9.32 \pm 0.16 \#$ \\
\hline 33 & $11.9 \pm 0.01 \#$ & $2.52 \pm 0.03$ \# & $9.86 \pm 0.19 \#$ \\
\hline \multirow[t]{2}{*}{34} & $10.3 \pm 0.01^{\star *}$ & $2.34 \pm 0.06^{* *}$ & $10.63 \pm 0.05^{*}$ \\
\hline & $8.7 \pm 0.07^{*}$ & $2.21 \pm 0.01^{\star \star}$ & $11.83 \pm 0.19^{* \star}$ \\
\hline
\end{tabular}

$\mathrm{n}=6$; values were expressed as mean \pm SEM

${ }^{*} \mathrm{p}<0.05 ;{ }^{* \star} \mathrm{p}<0.01$; \# non significant; $\bullet$ Control 